\section{FABRICATION AND CHARACTERISATION OF MG- ZN ALLOYS REINFORCED WITH CNF: A STUDY ON THE SINTERING PROCESS}

Herman Tuminoha,b, Muhammad Sallehuddin Mohd Azmana,b, Muhammad Al Kahfi Edrusa,b, Ahmad Kafrawi Nasutionc, Muhammad Hanif Ramlee $a, b *$

aMedical Devices and Technology Centre (MEDiTEC), Institute of Human Centered Engineering (iHumEn), Universiti Teknologi Malaysia, 81310 UTM Johor Bahru, Johor, Malaysia

bSchool of Biomedical Engineering and Health Sciences, Faculty of Engineering, Universiti Teknologi Malaysia, 81310 UTM Johor Bahru, Johor, Malaysia

cFaculty of Engineering, Muhammadiyah University of Riau, Pekanbaru, 28291, Riau, Indonesia
Article history

Received

18 March 2020

Received in revised form

29 September 2020

Accepted

30 September 2020

Published online

17 December 2020

*Corresponding author m.hanif@utm.my

\begin{abstract}
Nowadays, magnesium (Mg) based alloys have gained much interest due to its potential use as biodegradable implants for the application of fixation, screws and plates in orthopaedics field. The main problems of biodegradable implants made from pure Mg are its low strength and easily corrodible. Therefore, the purpose of this study was to analyse the sintering temperature of magnesium-zinc (Mg-Zn) alloys reinforced with carbon nanofibres (CNF) through mechanical and morphological structures. Pure Mg, Zn, and CNF was prepared via powder metallurgy (PM) method. The samples were mechanically alloyed using planetary ball mill to create finer powder. Next, the samples were compacted using the Instron machine for 10 minutes at room temperature to produce a 10 mm diameter cylindrical platelet. Then, the specimens were heated with an argon gas flow for 4 hours at different sintering temperatures. The results showed that the optimum sintering temperature for Mg-Zn alloys reinforced with $\mathrm{CNF}$ was at $250^{\circ} \mathrm{C}$ with elastic modulus and yield strength of $2729.886 \mathrm{MPa}$ and $140.628 \mathrm{MPa}$, respectively. The findings of this study concluded that Mg-Zn alloys reinforced with CNF composites have great potential to be used as new biodegradable implants for medical applications in the future.
\end{abstract}

Keywords: Magnesium, reinforcement, nanofibres, fabrication, composite, implant

(C) 2021 Penerbit UTM Press. All rights reserved

\subsection{INTRODUCTION}

Implants have been widely utilised in biomedical application such as orthopaedics, cardiovascular, cochlear and ophthalmic to improve the essential functions of the human body. To date, there are two types of implant materials, which are nondegradable and degradable materials. Unlike degradable materials, non-degradable materials such as titanium alloys and stainless steels do not decompose easily in the human body. Moreover, titanium alloys have relatively less resistance to wear and cause allergic tissue reactions due to fret [1].
Several other disadvantages of non-degradable orthopaedics implants have been found which include metal allergies, metal implant failures, and complications related to joint replacement [1].

Biodegradable materials are materials that are susceptible to degradation or reabsorption process of the metabolic fragments of the material under the influence of physiological reactions. The most common biodegradable materials for magnesium $(\mathrm{Mg})$ alloying are with calcium (Ca), zinc (Zn), tin (Sn) and manganese ( $\mathrm{Mn}$ ) as these elements are essential nutrients for the human body [3]. These alloys are widely used in orthopaedics, cardiovascular and 
tissue engineering applications [1-2]. It should be noted that the human body consists of $\mathrm{Mg}$, wherein $35 \%$ of $\mathrm{Mg}$ localised in the blood, while the remaining $65 \%$ of $\mathrm{Mg}$ can be found in the bones and teeth, which allows the Mg alloys to be safely placed in the human body [2]. Apart from that, the advantage of pure $\mathrm{Mg}$ correlates with its density, which is 1.74 $\mathrm{g} / \mathrm{cm}^{3}$ that is nearly similar to bone density $(1.8-2.0$ $\mathrm{g} / \mathrm{cm}^{3}$ ) [4] However, pure $\mathrm{Mg}$ possesses low elastic modulus with high rapid of degradation rate if applied into the human body [5]. From previous study, it was reported that Mg-Zn alloys showed some improvements on yield strength and at the same time could reduce hydrogen evolution during biocorrosion [3]. Moreover, Bommala et al. [2] revealed that $\mathrm{Mg}$ can degrade while simultaneously healing bone tissue breakage. If the orthopaedics implant is Mg based, hence no additional surgery is needed to remove the implant after the bone healing process takes place. However, pure Mg has a deficiency in mechanical properties in terms of strength. Therefore, a suitable element must be added to pure $\mathrm{Mg}$ in order to improve its mechanical properties. Other than the aforementioned biodegradable materials, there are several biomaterial implants that have been normally used for orthopaedics applications such as metallic, ceramic and polymer materials [1].

In order to optimise the strength, the combination of $\mathrm{Mg}$ with alloy composites can provide higher mechanical strength and resistance against corrosion as compared to pure Mg [3]. The advantage of $\mathrm{Mg}$ composites includes its toughness (around 1.6 times higher than hydroxyapatite) and degradable characteristics as the $\mathrm{Mg}$ itself is readily an essential nutrient to the human body [3]. The degradable metal matrix of $\mathrm{Mg}$ composites is a good property, which gives it the potential to become a great material for use in implant application [2]. Previous studies have revealed that several $\mathrm{Mg}$ composites can be composed with carbon nanofibres (CNF) and hydroxyapatite (HA) element $[3,5]$. The former element which is carbon can be known as a reinforcement particle for metal alloy due to its ability to escalate the strength properties of any composite materials [3]. It should be noticed that a study by Kobayashi et al. [18] found the use of carbon-based element, i.e. CNF, as reinforcement particle could possibly improve the strength of a metal matrix.

It is known that there are many methods available to develop $\mathrm{Mg}$ composites and one of them is powder metallurgy (PM) method [9]. This method consists of ball milling, compaction and sintering process to formulate the Mg composite. The sintering process is the most crucial step in PM method, which aims to form a solid material mass without melting it through liquefaction from heat or pressure for metals, ceramics, plastics, and other metals. The pressure during the sintering process could increase the degree of the bonding material; therefore, solid material mass is fully compact and form [9]. In this study, we utilised the PM method to develop the Mg composite.

The main purpose of this paper was to investigate the effects of sintering temperature for the fabrication of $\mathrm{Mg}$ alloy reinforced with carbon nanofibres (CNF) via PM method. The materials used in this study were pure Mg metal, Zinc (Zn) metal and CNF. The optimum sintering temperature was investigated in the range of 200 to $500^{\circ} \mathrm{C}$. The mechanical properties of the composites were evaluated by compressive test. The morphological structure of the composites was evaluated using scanning electron microscope (SEM) and energy dispersive $\mathrm{x}$-ray (EDX). This pilot study was aimed to provide valuable information to the medical industry and researchers in developing biodegradable implants from $\mathrm{Mg}$ composites for the treatment of bone fracture.

\subsection{METHODOLOGY}

\subsection{Fabrication of $\mathrm{Mg}$ Composite}

The fabrication of Mg composite was performed via Powder Metallurgy (PM) process. Firstly, pretreatment of $\mathrm{Mg}$-Zn alloys reinforced with CNF was conducted. The compositions are such that 96 wt.\% of pure Mg powder (99.67\% purity, Bendosen) and 4 wt.\% of pure Zn powder (99.67\% purity, Bendosen) was mixed with $10 \mathrm{~mL}$ of ethanol (Duran) using mechanical agitator. This composition was labelled as Matrix A. Meanwhile, a total of 2 wt.\% of CNF (Aldrich) was mixed in ethanol using ultrasonicator (performed at power of $50 \mathrm{~W}$ and frequency of $40 \mathrm{kHz}$ for a duration of 1 hour) where this solution was later labelled as Matrix B. The calculations of the compositions are shown in Equation (1), (2), (3), and (4).

$$
\begin{aligned}
& W_{M g-Z n}=98 \% \times W_{T} \\
& W_{C N F}=2 \% \times W_{T} \\
& W_{M g}=96 \% \times W_{M g-Z n} \\
& W_{Z n}=4 \% \times W_{M g-Z n}
\end{aligned}
$$

Where,

$\begin{array}{lll}W_{T}= & \text { Total weight of the composition } \\ W_{M g-Z n}= & \text { Total weight for Mg-Zn (Matrix A) } \\ W_{C N F}= & \text { Total weight for CNF (Matrix B) } \\ W_{M g}= & \text { Total weight for Mg }\end{array}$

After an hour of mixing process for Matrix A, Matrix $B$ was poured into a beaker of Matrix A by using mechanical agitator. Then, the samples were dried in an oven overnight at temperature of $60^{\circ} \mathrm{C}$. The $\mathrm{PM}$ method consists of three processes which are ball milling, compacting and sintering have been conducted. Planetary Ball Mill model PM100 (Retsch) was utilised for this process, and it has exploited both 
friction and impact of high centrifugal forces. Also, it will produce a rapid particle size reduction. The process was set at $220 \mathrm{rpm}$ for power rotation for 4 hours. The powder sample was poured into a grinding jar $(250 \mathrm{ml})$ with the stainless-steel beads $(22$ $\mathrm{mm}$ ). The selective speed of the ball mill based was referred to a previous study [5], which reported that the optimum compressive strength of the composite and lay within the limits of the mechanical strength required by natural bone.

After that, the samples were inserted into a mold for compaction process, wherein the samples were required to be in cylindrical form with a diameter of $10 \mathrm{~mm}$ and a height of $5 \mathrm{~mm}$. This compaction method was referred to American Society for Testing and Materials (ASTM), ASTM B925-15. Prior to compaction process, the load cell value was calculated following Equation (5) below. The samples were inserted into a jig with other tools and compressed at $400 \mathrm{MPa}$ to form a cylindrical shape for 10 minutes at room temperature using Universal Testing Machine, Instron 600DX. The compaction pressure was based on a previous finding where the most optimum pressure was at $400 \mathrm{MPa}$ [6].

Formula pressure equation,

$$
P \quad=\quad F / A
$$

Where,

$\begin{array}{lll}P & = & \text { Pressure } \\ F & = & \text { Force } \\ A & = & \text { Surface area of cylindrical }\left(\mathrm{mm}^{2}\right)\end{array}$

Lastly, the specimens were subjected to sintering process using Compact Split Tube Furnace BS-1200$50 \mathrm{X}$ machine. A total of 10 specimens were placed inside the tube alternately with ceramic rocks to avoid specimens from being in contact with each other during the process as shown in the Figure 1. To ensure the surface of the samples were protected from combustion and oxidation during sintering, the samples were placed in a closed tube and then vacuumed for 10 minutes. Then, argon gas was flowed into a tube with a flow of $10 \mathrm{~L} / \mathrm{min}$ for 4 hours at various temperatures ranging from $200^{\circ} \mathrm{C}, 250^{\circ} \mathrm{C}$, $300^{\circ} \mathrm{C}, 350^{\circ} \mathrm{C}, 400^{\circ} \mathrm{C}, 450^{\circ} \mathrm{C}$ and $500^{\circ} \mathrm{C}$. After that, the engine was left for 30 minutes for the cooling process. Finally, the specimens were taken from the tube and cooled at room temperature.

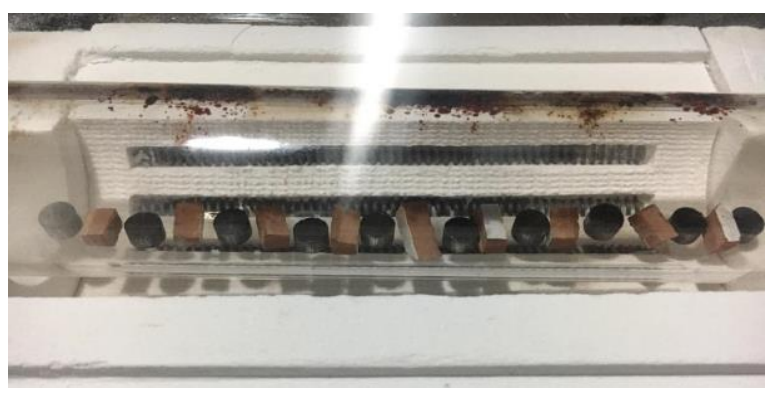

\subsection{Characterization}

Universal testing machine Instron 8874 with $25 \mathrm{kN}$ of load cell was used for compression test to identify the mechanical properties of the $\mathrm{Mg}-\mathrm{Zn}$ reinforced with CNF as shown in the Figure 2. This procedure was referred to ASTM-E9. In this study, two important mechanical elements were identified through this compression process where it was elastic modulus and yield strength. In the beginning, the specimens were placed on the base and the extension, wherein the load cell was stabilized. A displacement control test was applied at a velocity of $2.0 \mathrm{~mm} / \mathrm{s}$ at room temperature. All compressive tests were repeated three times for each sample.

For morphological analysis, scanning electron microscopy (SEM) and Energy Dispersive X-ray (EDX) (Model Hitachi Tabletop Microscope TM 3000, Japan) were used to analyze all samples. The experimental analysis was set at observation view and the magnification was set at 50X magnification. EDX analysis was used to observe the type of elements and percentage of elements present on the sample surfaces.

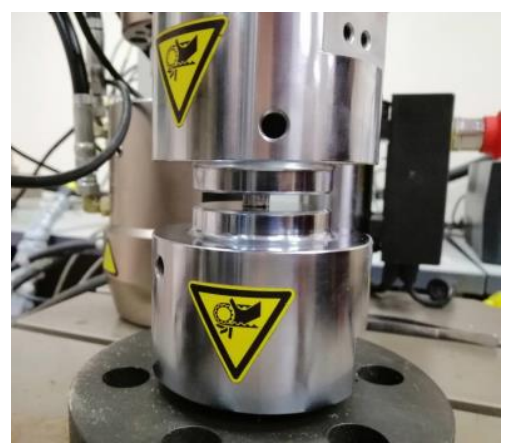

Figure 2 The specimen was placed on the load cell

\subsection{RESULTS AND DISCUSSIONS}

\subsection{Compression Test}

Figure 3 shows the average elastic modulus for all samples. Based on the diagram, the highest value of elastic modulus was found from the specimens that were sintered at $250^{\circ} \mathrm{C}(2729.89 \pm 212.69 \mathrm{MPa})$, meanwhile the lowest value was from specimens sintered at $450^{\circ} \mathrm{C}(1655.79 \pm 195.47 \mathrm{MPa})$. The other specimens that had been sintered at $300^{\circ} \mathrm{C}, 350^{\circ} \mathrm{C}$, and $400^{\circ} \mathrm{C}$ had a similar value of elastic modulus.

Figure 4 illustrates the yield strength for all seven different temperatures. Based on the bar chart, the highest yield strength was found from the specimens that were sintered at $250^{\circ} \mathrm{C}$ which was $140.28 \pm 21.69$ $\mathrm{MPa}$, while the lowest yield strength was $61.41 \pm 25.24$ $\mathrm{MPa}$ at $200^{\circ} \mathrm{C}$. On the other hand, there are two values of yield strength which are close to each other from the specimens sintered at $400^{\circ} \mathrm{C}$ and $450^{\circ} \mathrm{C}$ with

Figure 1 The specimens in the furnace tube 
the value of $130.725 \pm 17.37 \mathrm{MPa}$ and $128.0 .80 \pm 6.56$ $\mathrm{MPa}$, respectively.

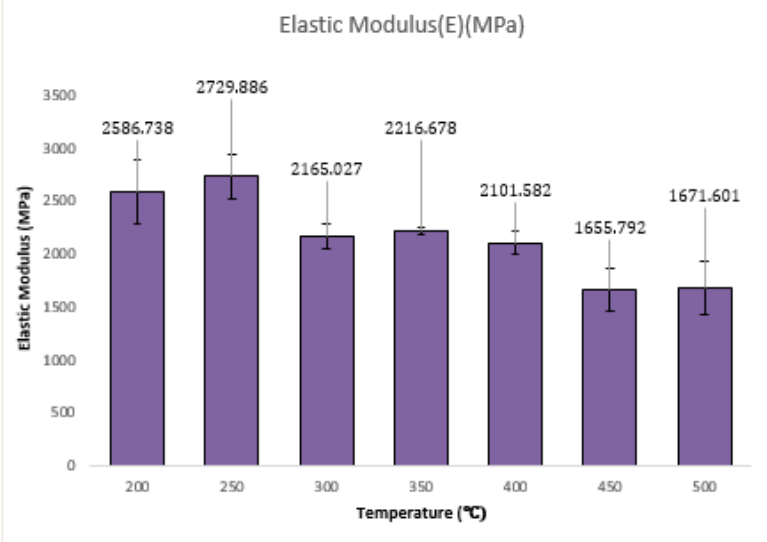

Figure 3 Elastic Modulus (E) by the level of sintering temperature

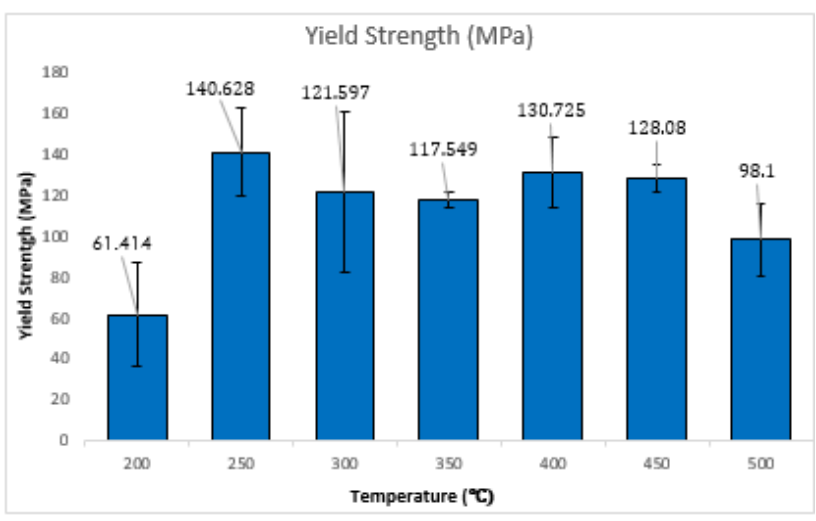

Figure 4 Yield strength by the level of sintering temperature

Based on the current results (Figure 3 and 4), it shows that the most optimum sintering temperature was at $250^{\circ} \mathrm{C}$. This justification is due to the specimen that was sintered with $250^{\circ} \mathrm{C}$ demonstrated highest magnitude of elastic modulus (2729.886 MPa) and yield strength (140.628 MPa). To the best of authors' knowledge, there are no similar studies had been conducted previously. Therefore, direct comparison between these findings and other scholar's results could not be discussed. However, there are some studies from the previous literatures, wherein the highest compressive strength and elastic modulus were found in the porous Mg-Zn scaffolds that had been sintered at $550^{\circ} \mathrm{C}$ [7]. A study conducted by Hoon et al. [8] reported that temperature of $640^{\circ} \mathrm{C}$ was the optimum condition for $\mathrm{Mg}$ composite reinforced with carbon nanotubes (CNT) with the yield strength of $119 \mathrm{Mpa}$.

It is known that the typical natural bone has an elastic modulus between 0.1 GPa and $20 \mathrm{GPa}$ [9], while the average yield strength of femur bone is 135 $\mathrm{MPa}$ [3]. In this study, the highest elastic modulus of Mg-Zn alloys reinforced with CNF was $2.7 \mathrm{GPa}$, which is within the abovementioned range. Besides, the modulus slowly decreased beyond the temperature of $250^{\circ} \mathrm{C}$. Moreover, the value of yield strength from almost all specimens in this recent study demonstrated low magnitude than average yield strength of femur bone (135 MPa) [3]. Nevertheless, there was one specimen had been sintered at $250^{\circ} \mathrm{C}$ that represented higher magnitude over the yield strength of the femur bone. As far as the authors are concerned, further studies must be conducted in the future especially on corrosion with animal testing to ensure the Mg-Zn alloys reinforced with CNF is safe to be used as implants without incurring a stress fracture or suffering damage at the constructs.

\subsection{Morphology and Composition}

Figure 5 show the result of microstructural properties and composition of $\mathrm{Mg}$-Zn composites via Scanning Electron Microscopy (SEM) and Energy Dispersive Xray (EDX). It is consisting of a solid solution of carbon (C) and $\mathrm{Zn}$ elements in the Mg composite. As shown in Figure 5, it can be observed that the microstructural surface of all specimens is fine grain, and each of them presented different features especially on the surface roughness. Based on same figure, the specimens made of $\mathrm{Mg}-\mathrm{Zn}$ alloys reinforced with CNF had low porosity and contains several elements. The EDX spectra and atomic percentage of elements listed in Figure 5 showed that the specimens consisted mainly of $\mathrm{Mg}$ and $\mathrm{C}$, and a small amount of $\mathrm{Zn}$ element. The presence of $C$ is due to the reinforcement of CNF used in this study. The highest peak observed in the EDX spectra of the specimens was Mg, followed by CNF and Zn. This is because when solid solution formation occurs, Zn which consists of smaller atoms appeared as impurities in the larger Mg atom lattice [10]. This can be observed from atomic percentage results as shown in Figure 5. In terms of strength and ductility, it must be high to achieve grain refinement, which is related to the presence of high frequency of low energy boundaries. Thus, the smaller the grain size, the higher the yield strength. The findings of this study are in agreement with those obtained by Seyedraoufi et al. [7] wherein the grain size of $\mathrm{Mg}-\mathrm{Zn}$ scaffolds increased when the temperature increased, which may reduce the strength properties [7]. In the present study, a similar phenomenon was observed when the sintering temperature was increased, which reduced the mechanical strength of $\mathrm{Mg}$ alloys. 


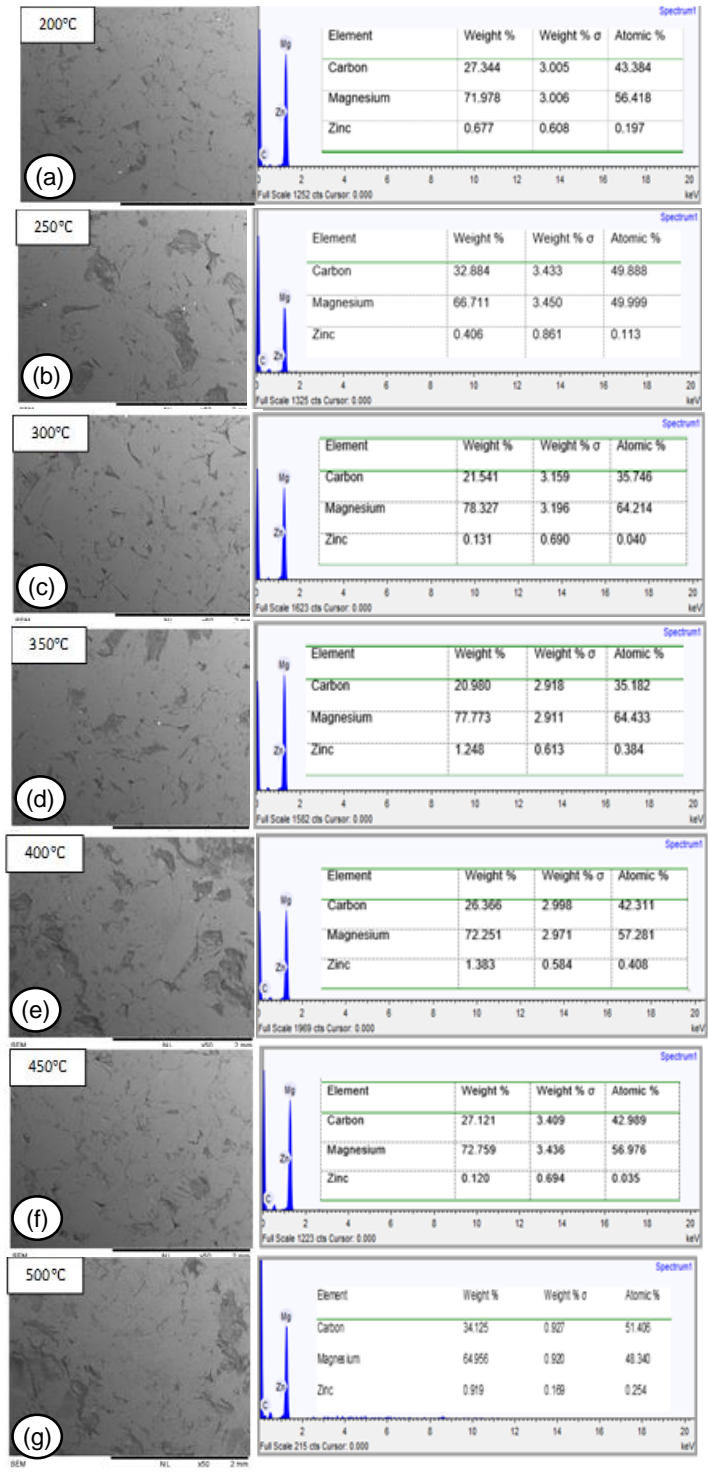

Figure 5 SEM images under 50X magnifications and EDX Characterization element of $\mathrm{Mg}$-Zn alloys reinforced with $\mathrm{CNF}$ with sintering temperature (a) $200^{\circ} \mathrm{C}$, (b) $250^{\circ} \mathrm{C}$, (c) $300^{\circ} \mathrm{C}$, (d) $350^{\circ} \mathrm{C}$, (e) $400^{\circ} \mathrm{C}$, (f) $450^{\circ} \mathrm{C}$ and (g) $500^{\circ} \mathrm{C}$

\subsection{CONCLUSION}

In this study, powder metallurgy method has been used to successfully fabricate and analyse the effects of Mg-Zn reinforced with CNF at different sintering temperatures. From the results, the optimum temperature was obtained at $250^{\circ} \mathrm{C}$ with the elastic modulus and yield strength of 2792MPa and 140MPa, respectively.

\section{Acknowledgement}

The authors would like to thank Universiti Teknologi Malaysia for providing the facilities and equipment to ensure this study is successfully conducted. Special thanks to Universiti Muhammadiyyah Riau, Indonesia for providing a sintering furnace during the fabrication process. This successful study has been sponsored by the Fundamental Research Grant Scheme (vote no. 5F135) under Ministry of Higher Education Malaysia, Universiti Teknologi Malaysia under Tier 2 Research University Grant (vote no. 15J84) and The Ministries of Research, Technology and Higher Education Republic of Indonesia through Director of Research and Community Service with the contract number: 009/L10/AK.04/KONTRAKPENELITIAN/2019.

\section{References}

[1] L. Berzina-Cimdina, M. Prakasam, J. Locs, A. Largeteau, D. Loca, and K. Salma-Ancane. 2017. Biodegradable Materials and Metallic Implants-A Review. J. Funct. Biomater. 8(4): 44.

[2] V. K. Bommala, M. G. Krishna, and C. T. Rao. 2018. Magnesium Matrix Composites for Biomedical Applications: A Review. J. Magnes. Alloy. 1-8.

[3] C. Godavitarne, A. Robertson, J. Peters, and B. Rogers. 2017. Biodegradable Materials. Orthop. Trauma. 31 (5): 316-320.

[4] E. Aghion. 2018. Biodegradable Metals. Metals (Basel). 8(10): 1-34.

[5] L. L. Soon, H. Zuhailawati, I. Suhaina, and B. K. Dhindaw. 2016. Prediction of Compressive Strength of Biodegradable Mg-Zn/HA Composite via Response Surface Methodology and Its Biodegradation. Acta Metall. Sin. English Lett. 29(5): 464-474.

[6] M. M. Yusof and H. Zuhailawati. 2017. The Effect of Compaction Pressure for on Properties of Binary and Ternary Magnesium Alloys. AIP Conf. Proc. 1865.

[7] Z. S. Seyedraoufi and S. Mirdamadi. 2013. Synthesis, Microstructure and Mechanical Properties of Porous MgZn Scaffolds. J. Mech. Behav. Biomed. Mater. 21: 1-8.

[8] M. Hoon, J. Wei, and M. Gupta. 2014. Interface Tailoring to Enhance Mechanical Properties of Carbon Nanotube Reinforced Magnesium Composites. J. Mater. 60: 490-495.

[9] D. Annur, F. P. Lestari, A. Erryani, and I. Kartika. 2018. Study of Sintering on Mg-Zn-Ca Alloy System. AIP Conf. Proc. 1964(May).

[10] E. M. Salleh, H. Zuhailawati, and S. Ramakrishnan. 2018. Synthesis of Biodegradable Mg - Zn Alloy by Mechanical Alloying: Statistical Prediction of Elastic Modulus and Mass Loss Using Fractional Factorial Design. Trans. Nonferrous Met. Soc. China. 28(4): 687-699.

[11] V. K. Bommala, M. G. Krishna, and C. T. Rao. 2018. Magnesium Matrix Composites for Biomedical Applications: A Review. J. Magnes. Alloy. 1-8.

[12] N. Saito et al. 2011. Application of Carbon Fibers to Biomaterials: A New Era of Nanolevel Control of Carbon Fibers After 30-Years of Development. Chem. Soc. Rev. 40(7): 3824-3834.

[13] Y. Grossmann and D. Madjar. 2002. Prosthetic Treatment for Severely Misaligned Implants: A Clinical Report. J. Prosthet. Dent. 88(3): 259-262,

[14] Saba, N., Jawaid, M., \& Sultan, M. T. H. 2019. An Overview of Mechanical and Physical Testing of Composite Materials. Mechanical and Physical Testing of Biocomposites, Fibre-Reinforced Composites and Hybrid Composites. Elsevier Ltd.

[15] Huang, T., Zheng, Y., \& Han, Y. 2016. Accelerating Degradation Rate of Pure Iron by Zinc Ion Implantation. Regenerative Biomaterials. 3(4): 205-215.

[16] Judson Durai, T., Sivapragash, M., \& Edwin Sahayaraj, M. 2017. Effect of Sintering Temperature on Mechanical 
Properties of Mg-Zr Alloy. International Journal of Mechanical and Production Engineering Research and Development. 7(5): 117-122.

[17] Khan, W., Gopala, V., Challa, S., Langer, R., \& Domb, A. J. 2014. Focal Controlled Drug Delivery. 3-32.

[18] Kobayashi, S., \& Kawai, W. 2007. Development of Carbon Nanofiber Reinforced Hydroxyapatite with Enhanced Mechanical Properties. Composites Part A: Applied Science and Manufacturing. 38(1): 114-123.

[19] Koç, E., Kannan, M. B., Ünal, M., \& Candan, E. 2015. Influence of Zinc on the Microstructure, Mechanical Properties and in Vitro Corrosion Behavior of Magnesium E
Zinc Binary Alloys. Journal of Alloys and Compounds. 648: 291-296.

[20] Li, G., Yang, H., Zheng, Y., Chen, X. H., Yang, J. A., Zhu, D., Takashima, K. 2019. Challenges in the Use of Zinc and Its Alloys as Biodegradable Metals: Perspective from Biomechanical Compatibility. Acta Biomaterialia. 97(5): 23-45.

[21] Li, Q., Viereckl, A., Rottmair, C. A., \& Singer, R. F. 2009. Improved Processing of Carbon Nanotube/Magnesium Alloy Composites. Composites Science and Technology. 69(7-8): 1193-1199. 